\title{
Metode Seasonal ARIMA untuk Meramalkan Produksi Kopi Dengan Indikator Curah Hujan Menggunakan Aplikasi R di Kabupaten Lampung Barat
}

\author{
The seasonal ARIMA method to forecast coffee production with rainfall indicators \\ uses application $\mathrm{R}$ in west Lampung regency \\ Hani Nastiti Tantika ${ }^{1}$, Nanang Supriadi, Dian Anggraini \\ Jurusan Pendidikan Matematika, Universitas Islam Negeri Raden Intan Lampung \\ 1hanitantika@yahoo.com
}

\begin{abstract}
Abstrak. Penelitian ini bertujuan untuk mendapatkan model terbaik dan meramalkan jumlah produksi kopi berdasarkan model terbaik yang telah diperoleh menggunakan metode Seasonal ARIMA yaitu dengan cara memodelkan data. Setelah diperoleh beberapa model pada masing-masing data, kemudian model terbaik dipilih berdasarkan pada kriteria nilai AIC dan SBC dengan nilai paling minimum. Hasil penelitian diperoleh untuk nilai AIC dan SBC yang paling minimum untuk data produksi kopi adalah model ARIMA $(1,2,0)(1,2,1) 12$ dan untuk data curah hujan adalah model ARIMA $(0,1,1)(1,1,0) 12$. Model tersebut adalah model yang akan digunakan untuk memprediksi jumlah kopi pada beberapa tahun mendatang di Kabupaten Lampung Barat.
\end{abstract}

Kata Kunci: seasonal ARIMA, peramalan, aplikasi R, kopi, lampung

Abstract. This research is used to get the best model and predict the amount of coffee production based on the best model that have been obtained by using seasonal ARIMA method. There are several steps of ARIMA seasonal method, the first is modeling data After obtaining several models on each data then the best model is chosen based on AIC and SBC value criteria with minimum value, minimum AIC and SBC value for coffee production data is ARIMA model $(1,2,0)(1,2,1) 12$ and for rainfall data is ARIMA model $(0,1,1)(1,1,0) 12$. The model is a model that will be used to predict the number of copies in the next few years in West Lampung District.

Keywords: seasonal ARIMA, forecasting, R application, coffee, lampung

\section{Pendahuluan}

Lampung Barat sedang berkembang pesat sebagai daerah penghasil kopi terbesar. Kopi merupakan tumbuhan yang banyak tumbuh dan di budidayakan di Lampung Barat, pembudidayaan kopi tidak hanya memerlukan keadaan tempat yang baik, pemberian pupuk sesuai dengan ketentuan, pengawasan terhadap biji kopi hingga menjelang panen tiba, kondisi iklim dan tanah saja tetapi ada faktor lain yang juga mempengaruhi pertumbuhan kopi yaitu faktor curah hujan yang juga sebagai faktor penentunya. Seperti yang diketahui bahwa produksi adalah penciptaan barang-barang dan jasajasa, meramalkan produksi berarti menentukan perkiraan besar kecilnya hasil produksi dimasa yang akan datang [8]. Oleh sebab itu, untuk dapat mengetahui bagaimana perkembangan jumlah produksi kopi di Kabupaten Lampung Barat pada masa yang akan datang, salah satu metode statistika yang dapat digunakan adalah analisis runtun waktu atau time series.

Time series merupakan serangkaian observasi terhadap suatu variabel yang diambil secara beruntun berdasarkan interval waktu yang tetap. Dasar pemikiran time series adalah pengamatan sekarang $\left(\boldsymbol{z}_{\boldsymbol{t}}\right)$ tergantung pada 1 atau beberapa pengamatan sebelumnya $\left(\boldsymbol{z}_{\boldsymbol{t}+\boldsymbol{k}}\right)$, dimana $\boldsymbol{t}$ adalah indeks waktu dari urutan pengamatan. Tahap-tahap Analysis Time Series yaitu yang pertama adalah proses Identifikasi model, identifikasi model dilakukan dengan membuat plot time series, dengan plot time series ini, kita akan mengetahui pola data dan trend deret pengamatan. Identifikasi model tidak hanya dilakukan dengan melihat plot data, tetapi harus pula disertai dengan pengetahuan mengenai data yang 
akan dianalisis. Yang kedua yaitu taksiran model, pada tahap taksiran model, kita memilih taksiran model yang baik. Dalam hal ini, menaksir model dilakukan dengan metode menaksir kuadrat terkecil, MSE, OLS dan maksimum likelihood. Kemudian yang terakhir adalah diagnosis model, model yang dibuat belum tentu sesuai dengan data yang dimiliki atau dengan asumsi dari model yang dibuat. Oleh karena itu, kita perlu mendiagnosis model yang telah dibuat dengan menyesuaikannya dengan hasil peramalan $[3,8,10]$.

\section{Tinjauan Pustaka}

\subsection{Stasioneritas}

Sebelum melakukan analisis, harus mengetahui terlebih dahulu apakah data time series yang digunakan sudah stasioner. Asumsi yang sangat penting dalam time series adalah stasioneritas deret pengamatan. Suatu deret pengamatan dikatakan stasioner apabila proses tidak berubah seiring dengan perubahan waktu. Maksudnya rata-rata deret pengamatan disepanjang waktu selalu konstan (Wei, 2006).

\subsection{Differencing}

Differencing adalah proses yang digunakan untuk mengatasi apabila data yang digunakan tidak stasioner dalam rata-rata [5].

\subsection{Transformasi Box-Cox}

Untuk menstabilkan varian dalam suatu data seri digunakan transformasi Box-Cox, Dengan transformasi ini kita mendefinisikan seri baru $Z^{\prime}{ }_{t}$ sebagai

$$
Z_{t}^{\prime}=\frac{z_{t^{\lambda}-1}}{\lambda}
$$

dimana $\lambda$ adalah bilangan real. Jika nilai $\lambda=1 / 2$ maka disebut transformasi akar karena $\boldsymbol{x}_{\boldsymbol{t}^{1 / 2}}$ adalah akar dari $\boldsymbol{z}_{\boldsymbol{t}}[5]$.

\subsection{Proses White Noise}

Proses White Noise merupakan proses stasioner. Proses White Noise didefinisikan sebagai deret variabel acak yang independen, identik dan terdistribusi. Suatu proses $\left\{\boldsymbol{\alpha}_{\boldsymbol{t}}\right\}$ disebut proses white noise jika data terdiri dari variabel acak yang tidak berkorelasi dan berdistribusi normal dengan rata-rata konstan [6].

\subsection{Model Autoregressive (AR)}

Model Autoregressive dengan order $p$ do notasikan $A R(p)$ didefinisikan sebagai:

$y_{t}=\phi_{1} y_{t-1}+\phi_{2} y_{t-2}+\cdots+\phi_{\mathrm{p}} \mathbf{y}_{t-p}+\varepsilon_{t}$

(i) Order pertama Autoregressive, $A R(1)$

Untuk Order Autoregressive $A R(1)$ dapat kita tulis :

$\boldsymbol{y}_{\boldsymbol{t}}=\boldsymbol{\phi}_{1} \mathbf{y}_{\boldsymbol{t}-1}+\boldsymbol{\varepsilon}_{\boldsymbol{t}}$

(ii) Order Kedua Autoregressive, $A R(2)$

Untuk Order Autoregressive $A R(1)$ dapat kita tulis :

$y_{t}=\phi_{1} y_{t-1}+\phi_{2} y_{t-2}+\varepsilon_{t}$ [7] 
2.6 Model Moving Average (MA)

Model moving average dengan order q dinotasikan $M A(q)$ didefinisikan sebagai

$$
y_{t}=\varepsilon_{t}-\theta_{1} \varepsilon_{t-1}-\theta_{2} \varepsilon_{t-2}-\theta_{3} \varepsilon_{t-3}-\cdots-\theta_{q} \varepsilon_{t-q} \quad ; \varepsilon_{t} \sim N\left(0, \sigma^{2}\right)
$$

(i) Order pertama Moving Average, $M A(1)$

Model paling sederhana dari Moving Average yakni MA(1) ketika nilai

$\mathrm{q}=1$

$y_{t}=\varepsilon_{t}-\theta_{1} \varepsilon_{t-1}$

(ii) Order kedua Moving Average, $M A(2)$

Model Moving Average lain adalah MA(2), yaitu :

$y_{t}=\varepsilon_{t}-\theta_{1} \varepsilon_{t-1}-\theta_{2} \varepsilon_{t-2},[7]$

2.7 Model Autoregressive Moving Average (ARMA)

Dalam bentuk umum, model Autoregressive Moving Average atau ARMA $(p, q)$ diberikan sebagai:

$y_{t}=\phi_{1} y_{t-1}+\phi_{2} y_{t-2}+\cdots+\phi_{p} y_{t-p}+\varepsilon_{t}-\theta_{1} \varepsilon_{t-1}-\theta_{2} \varepsilon_{t-2}-\cdots-\theta_{q} \varepsilon_{t-q}$

Dimana :

$y_{t}:$ nilai variabel pada waktu ke $-t$

$\phi_{i}:$ koefisien regresi $k e i=1,2,3, \ldots, p$

$\mathrm{P}:$ Order $A R$

$\theta_{i}=$ parameter model MA ke $i=1,2,3, \ldots, q$

$\mathrm{q}:$ Order $M A$

$\varepsilon_{t}, \varepsilon_{t-1, \varepsilon_{t-2}}, \ldots, \varepsilon_{t-q}:$ nilai error pada saat $t . t-1 . t-2 . t-q$ dan $\varepsilon_{t}$

diasumsikan white noise dan normal [6]

\subsection{Model Autoregresive Integrated Moving Average (ARIMA)}

Jika $d$ adalah bilangan bulat nonnegative, maka $\left\{x_{t}\right\}$ dikatakan proses ARIMA jika $Y_{t}=(1-$ $B)^{d} Z_{t}$ merupakan akibat dari proses ARMA. Definisi diatas berarti bahwa $\left\{y_{t}\right\}$ memenuhi persamaan :

$$
\phi_{p}(B)(1-B)^{d} Z_{t}=\theta_{q}(1-\theta \mathrm{B}) \varepsilon_{t},
$$

Persamaan (9) dapat kita tulis dengan operator B (Backshift) yaitu :

$$
1-B^{d}-\phi_{1} B-\phi_{1} B^{2}-\cdots-\phi_{p} B^{p} Z_{t}=\left(1+\theta_{1} B+\theta_{2} B^{2}+\cdots+\theta_{q} B^{q}\right) \varepsilon_{t}
$$

Sehingga diperoleh :

$$
1-B^{d} Z_{t}-\phi_{1} Z_{t-1}-\phi_{2} Z_{t-2}-\cdots-\phi_{p} Z_{t-p}=\varepsilon_{t}+\theta_{1} \varepsilon_{t-1}+\theta_{2} \varepsilon_{t-2}+\cdots+\theta_{q} \varepsilon_{t-q}
$$

\section{Dengan :}

$y_{t}:$ data observasi $k e-t$

$B$ : Operator backshift

$(1-B)^{d} z_{t}:$ time series yang stasioner pada pembedaan $k e-d$

$\varepsilon_{t}:$ nilai error pada waktu $k e-t$ 

$p:$ order AR
$q:$ order MA
$d:$ pembedaan, [6].

\subsection{Seasonal Proses}

Time series adalah data yang memiliki pola musiman. Ini sering terjadi ketika data mempunyai pola interval yang spesifik (bulan, minggu, dll). Salah satu cara untuk merepresentasikan data seperti ini adalah dengan mengasumsikan model yang mempunyai dua komponen yaitu :

$$
x_{t}=s_{t}+N_{t}
$$

dengan $s_{t}$ adalah komponen dengan faktor musiman s dan $N_{t}$ adalah komponen stokastik yang mungkin merupakan model ARMA [7].

\subsection{Pendugaan Parameter}

Maximum likelihood estimation merupakan salah satu metode dalam pendugaan parameter. Metode ini menggunakan prinsip memaksimumkan fungsi likelihood untuk menduga parameter $\theta$ dan $\phi$ pada model ARIMA. Diberikan bentuk umum model ARMA $(p, q)$ sebagai berikut :

$$
z_{t}=\phi_{1} z_{t-1}+\phi_{2} z_{t-2}+\cdots+\phi_{p} z_{t-p}+\alpha_{t}-\theta_{1} \alpha_{t-1}-\theta_{2} \alpha_{t-2}-\cdots-\theta_{q} \alpha_{t-q}
$$

Dimana $\dot{z}_{t}=z_{t}-\mu \operatorname{dan}\left\{a_{t}\right\} \sim N\left(0, \sigma_{a}^{2}\right)$, fungsi kepekatan peluang dari $\alpha=\alpha_{1}, \alpha_{2}, \ldots, \alpha_{n}$

didefinisikan sebagai berikut :

$$
P\left(\varepsilon \mid \phi, \mu, \theta, \sigma_{\varepsilon^{2}}\right)=\left(2 \pi \sigma_{\varepsilon^{2}}\right)^{\frac{n}{2}} \exp \left[-\frac{1}{2 \sigma_{\varepsilon^{2}}} \sum_{t-1}^{n} \varepsilon_{t^{2}}\right]
$$

Selanjutnya dapat dituliskan fungsi likelihood dari parameter $\left(\phi,,, \sigma_{\varepsilon^{2}}\right)$.

$$
\mathrm{nL}\left(\phi, \mu, \theta, \sigma_{a}^{2}\right)=-\frac{\mathrm{n}}{2} \ln 2 \pi \sigma_{a}^{2}-\frac{s(\phi, \mu, \theta)}{2 \sigma_{a}^{2}}
$$

dimana

$$
\mathrm{S}(\phi, \mu, \theta)=\sum_{\mathrm{t}=1}^{\mathrm{n}} \alpha_{\mathrm{t}}^{2}\left(\phi, \mu, \theta \mid \mathrm{Z}_{*}, \alpha_{*}, \mathrm{Z}\right)
$$

adalah sum square function. Nilai pendugaan $\hat{\phi}, \hat{\mu}$ dan $\hat{\theta}$ diperoleh ketika memaksimumkan persamaan (2.79) yang kemudian kita menyebut sebagai pendugaan maximum likelihood. Setelah diperoleh nilai pendugaan $\phi,$, maka dapat dihitung pula nilai pendugaan dari $\sigma_{\varepsilon^{2}}$ dari

$$
\sigma_{\varepsilon^{2}}=\frac{s(\hat{\phi}, \hat{\mu}, \hat{\theta})}{d f}
$$

Dengan $\boldsymbol{d} \boldsymbol{f}=(\mathbf{n}-\mathbf{p})-(\mathbf{p}+\mathbf{q}+\mathbf{1})=\mathbf{n}-(\mathbf{2} \mathbf{p}+\mathbf{q}+\mathbf{1}),[6]$.

\subsection{Kriteria Pemilihan Model Terbaik}

Salah satu pemilihan model terbaik dari beberapa model yang sesuai dapat berdasarkan nilai AIC (Akaike's Information Criterion) dan SBC (Schwarz Bayesian Criteria), rumus AIC dan SBC :

$$
\begin{aligned}
& \mathrm{AIC}=\mathrm{n} \ln \left(\hat{\sigma}_{\varepsilon}^{2}\right)+2(p+q+1), \hat{\sigma}_{\varepsilon}^{2}=\frac{S E E}{n} \\
& \mathrm{SBC}=\mathrm{n} \ln \left(\hat{\sigma}_{\varepsilon}^{2}\right)+2(p+q+1) \ln n
\end{aligned}
$$

dimana :

$$
M S E=\frac{\sum_{i=1}^{m}\left(x_{i}-\hat{x}_{i}\right)^{2}}{n}, m<n
$$




$$
S E E=\sum_{t=1}^{T}\left(x_{t}-\hat{x}_{t}\right)^{2}
$$

Nilai minimum pada AIC dan SBC mengindikasikan model terbaik [6].

Terdapat penelitian dengan metode yang serupa yaitu diantaranya adalah peramalan produksi kelapa sawit berdasarkan intensitas curah hujan menggunakan metode ARIMA (Autoregressive integrated moving average) studi kasus Kabupaten Morowali Sulawesi Tengah [1], Metode SARIMA Untuk Meramalkan produksi padi dengan indikator curah hujan di Kabupaten Boyolali Jawa Tengah periode 2012 [2], "Prediksi Kemunculan Titik Panas di Provinsi Riau Menggunakan Seasonal Autoregressive Integrated Moving Average (SARIMA) [4].

Berdasarkan penelitian yang terdahulu, dalam penelitian ini diterapkan juga metode yang sama yaitu metode Seasonal ARIMA dengan keterbaruan tentang adanya penggunaan aplikasi R dan objek yang di teliti berupa produksi kopi. Peneliti berharap dengan adanya metode Seasonal ARIMA ini bisa sedikit membantu masyarakat agar dapat merencanakan strategi dalam penyelesaian masalah yang terjadi dari berbagai keadaan iklim di masa yang akan datang agar masyarakat memiliki pilihan lain dan tidak bergantung pada hasil produksi kopi saja.

\section{Metode}

Metode Penelitian ini menggunakan studi literatur dan dilakukan secara sistematis yang diperoleh dari data dokumentasi berupa teks, buku-buku ataupun media lain untuk mendapatkan informasi sebanyak mungkin, kemudian melakukan simulasi sebagai aplikasi untuk menjelaskan teori yang telah didapat. Adapun langkah-langkah yang dilakukan pada penelitian yaitu sebagai berikut:

1) Menguji kestasioneran data dengan melihat plot data (time series plot) dan plot ACF (Autocorrelation Function).

2) Melakukan transformasi data yaitu dengan menggunakan metode Box-Cox apabila data digunakan tidak stasioner dalam varian.

3) Kemudian melakukan pembedaan pada data apabila data yang digunakan tidak stasioner dalam rata-rata.

4) Data dari hasil transformasi dan pembedaan kemudian diuji kestasionerannya dengan melihat plot data (time series plot) dan mengidentifikasi lag yang bernilai minimum pada plot ACF.

5) Menentukan orde model dengan melihat plot ACF (Autocorrelation Function) serta PACF (Parcial Autocorrelation Function)

6) Menetapkan model dugaan sementara berdasarkan orde model yang telah ditentukan sebelumnya.

7) Menduga parameter model dugaan sementara dengan menggunakan metode Maximum Likelihood Estimation (MLE).

8) Setelah itu menguji signifikansi parameter modelnya.

9) Uji signifikansi parameter menggunakan uji t dan p-value dengan kriteria pengambilan keputusan sebagai berikut : Tolak H0 jika $\left|\mathrm{t}_{\text {hitung }}\right|>t_{\frac{a}{2}}, d f$ dengan $d f=\mathrm{T}-\mathrm{p}$ dengan $\mathrm{T}$ adalah banyaknya data serta $\mathrm{p}$ adalah banyaknya parameter ada pada model.

10) Lakukan Pemeriksaan residual model yang apakah telah memenuhi proses white noise.

11) Melakukan pemilihan model terbaik Pemilihan model terbaik ini dapat dilihat dari nilai AIC(Akaike's Information Criterion) dan SBC (Schwarz Bayesian Criteria). Model dikatakan baik apabila AIC dan SBC bernilai minimum.

12) Melakukan peramalan atau forecasting Peramalan atau forecasting dapat dilakukan setelah diperoleh model terbaik. Adapun diagram alir dari metode penelitian tersebut adalah : 


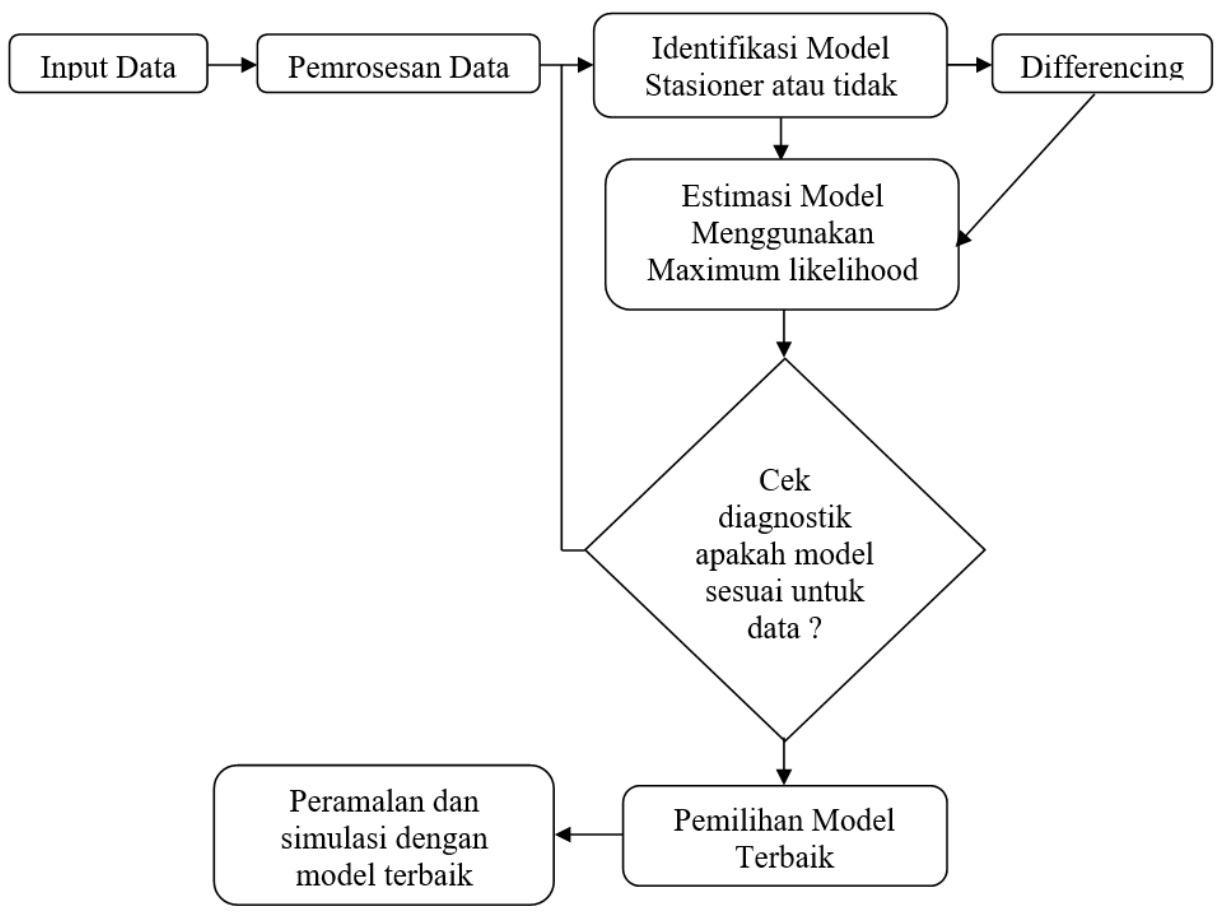

Gambar 1. Diagram alir metode penelitian

\section{Hasil dan Pembahasan}

Data yang dimaksud dalam penelitian ini adalah hasil yang diperoleh dari dokumentasi pada dinas perkebunan dan peternakan Provinsi Lampung serta Badan Meteorologi Klimatologi dan Geofisika, dengan hasil sebagai berikut (data yang digunakan yaitu data produksi kopi dan curah hujan). Pada proses pengolahan data dengan menggunakan metode Seasonal ARIMA yang dilakukan pada masingmasing data yaitu yang pertama untuk produksi kopi pada proses awal dimana pengujian kesetasioneran data, apabila pada proses pengujian tersebut data yang digunakan telah stasioner dalam rata-rata dan varian maka data tidak perlu dilakukan proses differencing dan transformasi. Sedangkan untuk data produksi kopi sendiri setelah dilakukan proses ksetasioneran ternyata data masih belum stasioner dalam rata-rata maupun dalam varian, sehingga diperlukan proses differencing sampai dua kali hingga data telah benar-benar stasioner dalam rata-rata dan transformasi box-cox digunakan untuk menstasionerkan data dalam varian.

Tabel 1

Rangkuman Hasil Estimasi Untuk Beberapa Model ARIMA

Data Produksi Kopi

\begin{tabular}{|c|c|c|}
\hline MODEL & AIC & SBC \\
\hline ARIMA $(1,2,0)(1,2,1)^{12}$ & 816,08 & 815,24 \\
\hline ARIMA $(1,2,1)(1,2,1)^{12}$ & 817,25 & 816,21 \\
\hline ARIMA $(1,2,2)(1,2,1)^{12}$ & 820,11 & 818,86 \\
\hline
\end{tabular}


Selanjutnya setelah data sudah bisa dikatakan stasioner dalam rata-rata maupun varian langkah selanjutnya adalah mengidentifikasi model dengan cara membuat plot ACF dan PACF dari data produksi kopi sehingga didapatkan model ARIMA $(p, d, q)(P, D, Q)^{S}$ yaitu ARIMA $(1,2,0)(1,2,1)^{12}$, ARIMA $(1,2,1)(1,2,1)^{12}$ ARIMA $(1,2,2)(1,2,1)^{12}$. Uji signifikansi parameter menggunakan uji t dan $p$-value dengan kriteria pengambilan keputusan sebagai berikut: Tolak H0 jika $\left|t_{\text {hitung }}\right|>t_{\frac{a}{2}}, d f$ dengan $d f=\mathrm{T}-\mathrm{p}$ dengan $\mathrm{T}$ adalah banyaknya data serta $\mathrm{p}$ adalah banyaknya parameter ada pada model. Sehingga setelah melewati proses estimasi dapat dilihat pada Tabel 1.

Berdasarkan tabel 1 dapat dilihat bahwa, model yang baik dipilih berdasarkan kriteria bahwa model terbaik adalah model dengan nilai AIC dan BIC/SBC paling minimum. Berdasarkan rangkuman hasil estimasi diatas dapat dilihat bahwa nilai dari AIC dan $\mathrm{ABC}$ paling minimum adalah model ARIMA $(1,2,0)(1,2,1)^{12}$ sehingga dapat disimpulkan bahwa model terbaik untuk data produksi kopi yaitu ARIMA $(1,2,0)(1,2,1)^{12}$. Sehingga setelah didapatkan model terbaik, proses yang terakhir adalah peramalan dengan model terbaik produksi kopi yaitu ARIMA $(1,2,0)(1,2,1)^{12}$ dengan hasil peramalan dapat dilihat pada Tabel 2.

Tabel 2

Rangkuman Hasil Permalan Data Produksi Kopi

\begin{tabular}{|c|c|c|c|}
\hline TAHUN & ACTUAL DATA & TAHUN & PERAMALAN \\
\hline 2006 & 55.995 & 2016 & 97790,04 \\
\hline 2007 & 56.227 & 2017 & 195162,34 \\
\hline 2008 & 56.227 & 2018 & 361401,82 \\
\hline 2009 & 61.201 & 2019 & 613222,71 \\
\hline 2010 & 61.215 & 2020 & 967323,28 \\
\hline 2011 & 61.230 & 2021 & 1440404,99 \\
\hline 2012 & 61.219 & 2022 & 2049168,71 \\
\hline 2013 & 52.576 & 2023 & 2810315,38 \\
\hline 2014 & 42.748 & 2024 & 3740545,97 \\
\hline 2015 & 52.647 & 2025 & 4856561,41 \\
\hline
\end{tabular}

Berdasarkan tabel 2 diatas dapat dilihat bahwa untuk peramalan hasil produksi kopi tertinggi berada pada tahun 2025 dengan nilai mencapai 4.856561,41 ton/tahun dan untuk hasil produksi terendah yaitu pada tahun 2006 dengan nilai mencapai 97.790,04 ton/tahun.

Untuk data yang ke dua adalah data curah hujan sama halnya dengan data produksi kopi pada proses awal yaitu pengujian ksetasioneran data, apabila pada proses pengujian tersebut data yang digunakan telah stasioner dalam rata-rata dan varian maka data tidak perlu dilakukan proses differencing dan transformasi, sedangkan untuk data currah hujan sendiri setelah dilakukan proses ksetasioneran ternyata data masih belum stasioner dalam rata-rata maupun dalam varian, sehingga diperlukan proses differencing hanya satu kali hingga data telah benar-benar stasioner dalam rata-rata dan transformasi box-cox digunakan untuk menstasionerkan data dalam varian. Kemudian setelah data sudah bisa dikatakan stasioner dalam rata-rata maupun varian langkah selanjutnya adalah mengidentifikasi model dengan cara membuat plot ACF dan PACF dari data curah hujan sehingga didapatkan model ARIMA $(p, d, q)(P, D, Q)^{S}$ yaitu ARIMA $(1,1,0)(1,1,0)^{12}$, ARIMA $(1,1,1)(1,1,0)^{12}$ ARIMA $(0,1,1)(1,1,0)^{12}$. Uji signifikansi parameter menggunakan uji t dan $p$-value dengan kriteria pengambilan keputusan sebagai berikut : Tolak H0 jika $\left|t_{\text {hitung }}\right|>t_{\frac{a}{2}}, d f$ dengan $d f=$ T-p dengan $T$ adalah banyaknya data serta $\mathrm{p}$ adalah banyaknya parameter ada pada model. Sehingga setelah melewati proses estimasi dapat dilihat pada Tabel 3. 
Tabel 3

Rangkuman Hasil Estimasi Untuk Beberapa Model ARIMA

Data Curah hujan

\begin{tabular}{|c|l|l|}
\hline MODEL & AIC & SBC \\
\hline ARIMA $(1,1,0)(1,1,0)^{12}$ & $-36,79$ & $-36,55$ \\
\hline ARIMA $(1,1,1)(1,1,0)^{12}$ & $-38,09$ & $-37,77$ \\
\hline ARIMA $(0,1,1)(1,1,0)^{12}$ & $-39,84$ & $-39,6$ \\
\hline
\end{tabular}

Berdasarkan tabel 3 dapat dilihat bahwa, model yang baik dipilih berdasarkan kriteria bahwa model terbaik adalah model dengan nilai AIC dan BIC/SBC paling minimum. Berdasarkan rangkuman hasil estimasi diatas dapat dilihat bahwa niali dari AIC dan SBC paling minimum adalah model ARIMA $(0,1,1)(1,1,0)^{12}$ sehingga dapat disimpulkan bahwa model terbaik untuk data curah hujan yaitu ARIMA $(0,1,1)(1,1,0)^{12}$. Sehingga setelah didapatkan model terbaik, proses yang terakhir adalah peramalan dengan model terbaik curah hujan yaitu ARIMA $(0,1,1)(1,1,0)^{12}$ dengan hasil peramalan dapat dilihat pada Tabel 4 .

Tabel 4

Rangkuman Hasil Permalan Data Produksi Kopi

\begin{tabular}{|c|c|c|c|}
\hline TAHUN & ACTUAL DATA & TAHUN & PERAMALAN \\
\hline 2006 & $2.030,6$ & 2016 & 1420,6113 \\
\hline 2007 & $2.272,2$ & 2017 & 1365,1599 \\
\hline 2008 & $1.928,5$ & 2018 & 1294,9994 \\
\hline 2009 & 2.696 & 2019 & 1229,0047 \\
\hline 2010 & $2.913,5$ & 2020 & 1161,8302 \\
\hline 2011 & 1.835 & 2021 & 1094,9898 \\
\hline 2012 & 1.716 & 2022 & 1020,0548 \\
\hline 2013 & 2.628 & 2023 & 961,1465 \\
\hline 2014 & 1.452 & 2024 & 894,2307 \\
\hline 2015 & 1.528 & 2025 & 827,3170 \\
\hline
\end{tabular}

Berdasarkan tabel 4 diatas dapat dilihat bahwa untuk peramalan curah hujan tertinggi berada pada tahun 2016 dengan nilai mencapai 1420,6113 mm dan untuk curah hujan terendah yaitu pada tahun 2025 dengan nilai mencapai 827,3170mm.

Untuk mengetahui apakah ada korelasi antara produksi kopi dengan indikator curah hujan maka kita dapat mengujinya dengan menggunakan uji korelasi dari variabel tersebut, berikut adalah output dari hasil uji korelasi untuk data produksi kopi dengan indikator curah hujan di Kabupaten Lampung Barat dengan menggunakan aplikasi R.2.11.1 dengan menggunakan data yang telah melewati proses transformasi: 


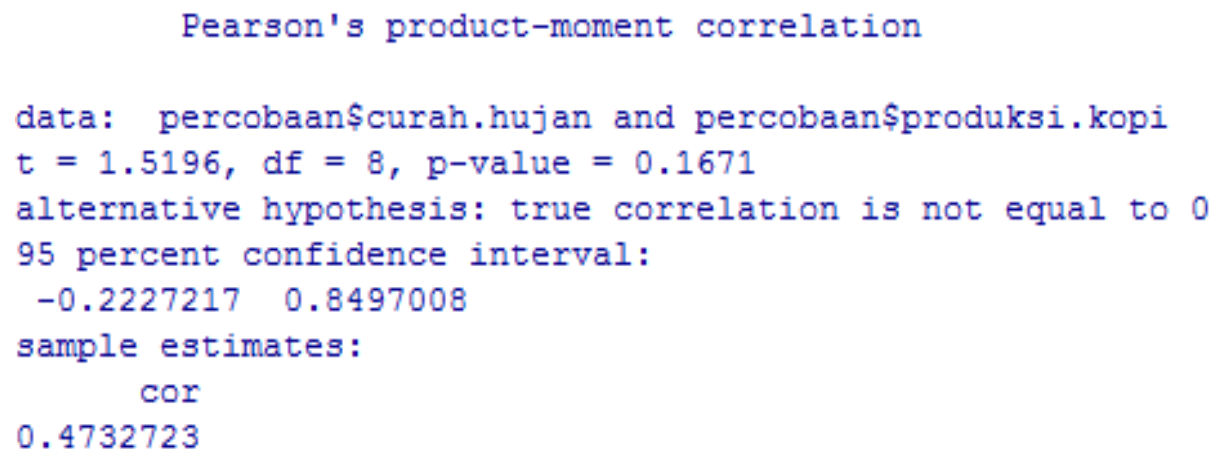

Gambar 2. Hasil dari uji pearson's product moment correlation.

Berdasarkan Gambar 2 di atas dapat dapat dilihat bahwa nilai $p$-value $=0,1671$, menurut jonathan sarwono terdapat kekuatan hubungan korelasi yaitu sebagai berikut :

1. $0,00-0,199=$ Sangat rendah

2. $0,20-0,399=$ Rendah

3. $0,40-0,599=$ Sedang

4. $0,60-0,799=$ Kuat

5. $0,80-1,00=$ Sangat kuat

Dengan hipotesis adalah :

$H_{0}$ : tidak ada hubungan antara produksi kopi dengan indikator curah hujan

$H_{1}$ : ada hubungan antara produksi kopi dengan indikator curah hujan

Kriteria penolakan :

Tolak $H_{0}$ jika nilai signifikansi $\mathrm{p}-$ value $<\alpha=0,05$

Berdasarkan penjelasan diatas didapat bahwa nilai dari $t$-tabel $=1,833$ dan $t$-hitung $=$ 1,5196. sehingga dapat disimpulkan bahwa $t-$ hitung $<t-$ tabel atau $1,5196<1,833$ sehingga $H_{0}$ diterima yang artinya bahwa tidak ada hubungan antara produksi kopi dengan indikator curah hujan dengan kekuatan hubungan korelasi sedang dengan koefisien korelasi sebesar 0,4732723.

\section{Kesimpulan dan Saran}

Berdasarkan pengolahan data yang telah dilakukan oleh peneliti, maka dapat disimpulkan bahwa model terbaik yang digunakan untuk data produksi kopi adalah ARIMA $(1,2,0)(1,2,1)^{12}$ dan untuk data curah hujan sendiri adalah ARIMA $(0,1,1)(1,1,0)^{12}$. Serta berdasarkan proses dari metode seasonal ARIMA telah terbukti bahwa hasil dari produksi kopi itu di pengaruhi oleh intensitas curah hujan yang turun, hujan dengan kekuatan hubungan korelasi yang sangat lemah dengan nilai korelasi 0,4732723 dengan hubungan korelasi sedang. Untuk hasil produksi kopi terbesar itu pada tahun 2025 dengan hasil produksi yaitu sebesar 4.856561,41 ton dengan curah hujan sebesar 827,3170 mm dan terendah terjadi pada tahun 2016 dengan hasil mencapai 97.790,04 ton dengan curah hujan sebesar $1420,6113 \mathrm{~mm}$.

Berdasarkan kesimpulan diatas terdapat kekurangan pada penelitian ini dan terdapat saran untuk peneliti selanjutnya yaitu: Kekurangan penelitian ini yaitu sulit mendapatkan data karena 
keterbatasan data yang ada di Dinas Perkebunan dan Peternakan Provinsi Lampung karena dinas telah mengakumulasikan data dari seluruh Kabupaten atau Kota yang ada di Provinsi Lampung menjadi 1 dan dinas tidak menyimpan arsip per Kecamatan penghasil kopi sehingga hanya ada tersisa 10 tahun terakhir saja. Untuk pengembangan selanjutnya maka peneliti lain dapat menambahkan banyaknya data yang digunakan untuk proses peramalan pada tahun yang akan datang agar mendapatkan hasil yang lebih signifikan.

\section{Referensi}

[1] H Bando, S Prasetyo, "Peramalan Produksi Kelapa Sawit Berdasarkan Intensitas Curah Hujan Menggunakan Metode ARIMA (Autoregressive Integrated Moving Average) Studi Kasus Kabupaten Morowali Sulawesi Tengah", Artikel Ilmiah, Universitas Kristen Satya Wacana Salatiga, 2012. h.19.

[2] A Apriyadi, S Prasetyo, "Metode SARIMA Untuk Meramalkan Produksi Padi Dengan Indikator Curah Hujan Kabupaten Boyolali Jawa Tengah Periode 2012", Laporan Penelitian, Universitas Kristen Satya Wacana Salatiga, 2012. h.8.

[3] N Iriawan, SP Astuti. "Mengolah Data Statistik Dengan Mudah Menggunakan Minitab 14", Yogyakarta: C.V Andi Offset, 2006.

[4] N Istiqomah, "Prediksi Kemunculan Titik Panas Di Provinsi Riau Menggunakan Seasonal Autoregressive Integrated Moving Average (SARIMA)", Skripsi, Institut Pertanian Bogor, 2015. h.19.

[5] A Pankratz, "Forecasting With Dynamic Regression Models", Canada: Willey Intersciences Publication, 1991. h.27.

[6] Wei, WS William, "Time Series Analysis Univariate And Multivariate Method", 2nd ed. Canada: Pearson eddison Wesley, 2006. h.10.

[7] DC Montogomery, CL Jennings, M Kulahci, "Introduction Time Series Analysis and Forecasting", New Jersey: Wiley Interscience, 2008. h.57.

[8] FH Badruzzaman, E Harahap, E Kurniati, MD Johansyah, "Pengendalian Persediaan Produksi Hijab Berdasarkan Economic Production Quantity di RAR Azkia", Jurnal Matematika Universitas Islam Bandung, Vol 16 No 2, 2017.

[9] IL Nur'aini, E Harahap, FH Badruzzaman, D Darmawan, "Pembelajaran Matematika Geometri Secara Realistis Dengan GeoGebra", Jurnal Matematika Universitas Islam Bandung, Vol 16 No 2, 2017.

[10] MY Fajar, E Harahap, FH Badruzzaman, "Penentuan EOQ Masalah Persediaan Multi-Item Dengan NonLinear Goal Programming”, Jurnal Matematika Universitas Islam Bandung, Vol 6 No 1, 2007. 